\title{
Quem é quem na formação da população paranaense: Um estudo de relações sociais nos Setecentos ${ }^{1}$.
}

Resumo: Por meio desta investigação procura-se, de uma certa forma, articular a utilização de fontes documentais na pesquisa histórica com outros campos do conhecimento científico, como por exemplo os estudos demográficos, a fim enriquecer e ampliar perspectivas do campo historiográfico. Para concretizar tal plano, análises a respeito de um vasto conjunto de listas nominativas de habitantes do século XVIII (mais precisamente do ano de 1793) foram efetivadas com o intento de apurar a compreensão da sociedade colonial curitibana. As questões intrínsecas nessa problemática são muito caras ao CEDOPE (Centro de Documentação e Pesquisa dos Domínios Portugueses), pois se deseja aqui entender certas articulações existentes dentro das relações sociais, salientando neste caso "quem" seriam seus "atores". Uma das motivações principais para o exercício de tal estudo foi dada pela busca de um dos personagens chave para a pesquisa: Gregório Gonçalves. A partir de esforços efetivados para encontrá-lo em registros paroquiais e em listas nominativas pôde-se, com as informações auferidas, compreender-se um pouco melhor a conjuntura a qual o mesmo estava inserido. Nessa direção, busca-se enriquecer o debate presente dentro das formulações acerca da estruturação colonial brasileira, sendo neste caso privilegiado o contexto da 5a Comarca da Capitania de São Paulo. Conseqüentemente, com a transcrição dos censos informações puderam ser catalogadas e expostas ao debate historiográfico. Assim, muitos dados coletados auxiliam a tentativa de deslindar a trama das relações sociais estabelecidas a partir de nosso "protagonista”, o mestiço Gregório Gonçalves.

A busca pela compreensão de um determinado contexto histórico é fundamental na tentativa de interpretação de estruturas sociais. Nessa perspectiva, esforços voltados para a descoberta de características particulares de cada "recorte temporal" , como é o caso aqui apresentado, possibilitam a elaboração de estudos referentes a fragmentos da História extremamente relevantes. Portanto, o "estudo de caso" se torna uma ferramenta intrínseca a pesquisa histórica, auxiliando-a em diversos aspectos. Assim sendo, essa é - de forma resumida, diga-se de passagem - a proposta aqui adotada.

Referente a historiografia, as obras adotadas para tal estudo proporcionaram uma visão ampla do contexto a ser analisado, sendo utilizados textos que auxiliam e possibilitam a expansão das perspectivas do historiador. Caio Prado Júnior, em Formação do Brasil Contemporâneo; Maria Luiza Marcílio, em Crescimento demográfico e evolução agrária paulista 1700-1836 são apenas dois exemplos da bibliografia utilizada, sendo a primeira obra citada mais abrangente e a seguinte voltada, de certa forma, ao objeto a ser discutido posteriormente. É lógico que um número maior de obras foi utilizado no desenvolvimento parcial desta pesquisa, e as mesmas serão referenciadas e relatadas em um momento mais oportuno.

Em suma, pretende-se, além dos objetivos intrínsecos na problemática do estudo, a preservação, por via da transcrição e digitalização, de uma documentação extremamente rica em informações do passado "colonial paranaense".

A documentação utilizada nesta investigação constitui, para algumas regiões, uma das principais fontes de dados referentes ao contexto colonial brasileiro. Usufruindo desse fato, procurei efetivar inicialmente um levantamento das características básicas das referidas fontes com o intento de averiguar aspectos que possibilitassem a estruturação de um método referente à análise das mesmas. Dessa forma seria possível, pelo menos em um plano inicial, constatar certos padrões existentes na estruturação do documento e na sua formatação.

\footnotetext{
${ }^{1}$ Este artigo busca apresentar os resultados parciais auferidos da pesquisa que está sendo efetivada sob a orientação do Professor Doutor Sérgio Odilon Nadalin do Departamento de História da Universidade Federal do Paraná. O estudo, por sua vez, é referente ao plano de trabalho apresentado à Comissão de Iniciação Científica da Universidade Federal do Paraná em agosto de 2003.

${ }^{2}$ Bolsista de Iniciação Científica/ CNPq da Universidade Federal do Paraná.
} 
Conseqüentemente, o historiador se depara aqui com uma armadilha, pois a estruturação adotada pelos recenseadores no caso das listas nominativas aqui utilizadas muitas vezes "obscurece" informações relevantes para o processo interpretativo. ${ }^{3}$ Assim sendo, as listas aqui empregadas são, ao mesmo tempo, fontes ricas em informações diversas; mas, simultaneamente, dificultam sua utilização.

Saber as características da população por meio desses censos era fundamental para se almejar um controle maior por parte da administração governamental no período moderno. Nessa direção, saliento que as listas nominativas utilizadas referentes ao ano de 1793, não apresentam informações no que diz respeito às ocupações dos habitantes. Tais dados viriam a ser implementados na documentação anos mais tarde. Os censos em referência estão centrados principalmente no objetivo da contagem da população e de sua estrutura domiciliar.

\begin{tabular}{|c||c|c|c|c|c|c|}
\hline $\mathbf{N}^{\mathbf{0}}$ & NOME & CAT & ID & EC & S & OBSERVAÇÃO \\
\hline \hline$[01]$ & Manuel da S. ${ }^{A}$ (SILVA) & Chefe & 52 & C & M & Possui 01 escravo. \\
\hline & Maria DINIZ & Esposa & 50 & C & F & Alferes. \\
\hline & $\begin{array}{c}\text { Francisco) da S. }{ }^{\mathrm{A}} \text { (SILVA) } \\
\text { [LEIRIA?] }\end{array}$ & Filho & 33 & S & M & \\
\hline Antonio & Filho & 25 & S & M & \\
\hline & Marcos & Filho & 20 & S & M & \\
\hline & Manuel & Filho & 18 & S & M & \\
\hline & Joaquim & Filho & 16 & S & M & \\
\hline & Ursula & Filha & 27 & S & F & \\
\hline & Maria & Filha & 12 & S & F & \\
\hline & Maria & Filha & 10 & S & F & \\
\hline & Roza & Agreg. & 50 & $?$ & F & \\
\hline & Vitoria & Agreg. & 15 & ? & F & \\
\hline
\end{tabular}

Observação: CAT = "categoria"; ID = "idade"; EC = "estado civil". S = "gênero".

Creio ser importante salientar certos aspectos incutidos neste trecho de documentação acima destacado. O padrão aqui adotado difere da lista propriamente dita, pois, em primeiro lugar, trata-se de uma metodologia adotada pelo $\mathrm{CEDOPE}^{4}$ que visa facilitar a transcrição da documentação utilizando categorias que nas fontes não são ilustradas. Pelo menos não mencionadas da forma acima exposta.

No exemplo, temos um “domicílio completo" constituído pelo "chefe”, no caso Manuel da Silva, sua esposa, filhos, agregados e um escravo. Como se trata de um proprietário de escravo, podemos supor que o mesmo detenha um certo "status" na sociedade, visto que no contexto aqui analisado os detentores de cativos não são muito numerosos.

Ainda utilizando a documentação acima podemos abordar algumas questões a respeito dos agregados. Caio Prado Júnior caracteriza os mesmos da seguinte forma:

“(...) nas cidades, mas sobretudo no campo, se encostam a algum senhor poderoso, e em troca de pequenos serviços, às vezes até unicamente de sua simples presença própria a aumentar a clientela do chefe e inuflar-lhe a vaidade, adquirem o direito de viver à sua sombra e receber proteção e auxílio. São então os chamados agregados, os moradores dos engenhos”.

É óbvio que muitos aspectos mencionados na obra em questão já estão superados historiograficamente. Entretanto, tal afirmação foi escolhida com o intento de demonstrar que a sociedade colonial brasileira, em sua totalidade, era extremamente patriarcal. Essa característica, para Caio Prado Júnior, representaria o sentido da colonização buscado pelos países europeus e marcaria tanto o período colonial brasileiro como as fases imperial e

\footnotetext{
${ }^{3}$ Maria Luiza Marcílio destaca que o modelo das listas nominativas de 1775 a 1797 era o seguinte:

1. ${ }^{0}$ ) Crianças do sexo masculino de zero a sete anos; $2^{0}$ ) Rapazes de sete a quinze anos; $3^{0}$ ) Homens de quinze a sessenta anos; $4^{0}$ ) Velhos de sessenta anos e mais; $5^{0}$ ) Crianças do sexo feminino de zero a sete anos; $6^{0}$ ) Raparigas de sete a catorze anos; $7^{0}$ ) Mulheres de quatorze a quarenta anos; $8^{0}$ ) Adultas e velhas de quarenta anos ou mais; $9^{0}$ ) Nascimentos do ano; $10^{0}$ ) Mortes do ano. Pp. 37 e 38.

4 “Centro de Documentação e Pesquisa de História dos Domínios Portugueses”, do Departamento de História da UFPR.

${ }^{5}$ JÚNIOR, Caio Prado. Formação do Brasil Contemporâneo, Colônia. São Paulo : Brasiliense, 1961. p 281.
} 
republicana subseqüentes: "o patriarcalismo se encontra nas instituições portuguesas e, ao mesmo tempo, floresceu no Brasil devido ao meio local em que se constitui. Esse grande domínio torna-se a célula orgânica da sociedade colonial." 6

Tal discussão remete a diversas questões como, por exemplo, as interpretações e indagações efetivadas por Carlos Prado de Almeida Bacellar a respeito da agregação. Em curso ministrado recentemente na Universidade Federal do Paraná, considerou as análises efetivadas até agora sobre este tema insatisfatórias. Ou seja, ele não vê o agregado como sendo pertencente a uma categoria devido a inúmeras possibilidades existentes nesse fenômeno. Assim sendo, o mesmo não seguiria um padrão único, fato que tornaria impossível conferir-lhe uma homogeneidade. Ademais, nessa perspectiva, a agregação seria uma medida provisória.

Uma oportunidade em que pode ser constatada essa característica está ligada diretamente com o "personagem chave” para esta pesquisa, Gregório Gonçalves. No trecho de documentação a seguir é possível observar a presença de um agregado no domicílio de Gregório, fato até então inédito visto que o mesmo já havia sido localizado em pesquisas anteriores em um conjunto de cerca de dez listas nominativas e, em nenhuma delas, havia a presença de qualquer agregado em seu domicílio ${ }^{8}$. Ainda referente a este caso pode-se perceber que Narçiza (sic.) aparece como agregada de Sebastião Alvares/Alves - "compadre” de Gregório e Anna Maria como será demonstrado a seguir - reforçando assim, a possibilidade de uma agregação apenas temporária.

\begin{tabular}{|c|c|c|c|c|c|c|}
\hline \multirow[t]{13}{*}{ [10] } & $\begin{array}{c}\text { Gregorio GLZ (GONÇALVES) } \\
\text { TRONES }\end{array}$ & Chefe & 44 & $\mathrm{C}$ & $\mathrm{M}$ & \\
\hline & Anna Maria & Esposa & 40 & C & $\mathrm{F}$ & \\
\hline & Felisberto & Filho & 21 & $\mathrm{~S}$ & $\mathrm{M}$ & \\
\hline & Bento & Filho & 19 & $\mathrm{~S}$ & $\mathrm{M}$ & \\
\hline & João & Filho & 13 & $\mathrm{~S}$ & $\mathrm{M}$ & \\
\hline & Felizardo & Filho & 4 & $\mathrm{~S}$ & $\mathrm{M}$ & \\
\hline & Maria & Filha & 14 & $\mathrm{~S}$ & $\mathrm{~F}$ & \\
\hline & Roza & Filha & 10 & $\mathrm{~S}$ & $\mathrm{~F}$ & \\
\hline & Maria & Filha & 6 & $\mathrm{~S}$ & $\mathrm{~F}$ & \\
\hline & Maria & Filha & 2 & $\mathrm{~S}$ & $\mathrm{~F}$ & \\
\hline & Joanna & Filha & 1 & $\mathrm{~S}$ & $\mathrm{~F}$ & \\
\hline & Narçiza & Agreg. & 46 & $\mathrm{~S}$ & F & $\begin{array}{c}\text { Agregada de Seb }^{\text {am }} \text { (Sebastião) Alz } \\
\text { (ALVARES/ALVES) }\end{array}$ \\
\hline & Antonio & Filho & 22 & $\mathrm{~S}$ & $\mathrm{M}$ & Filho da agregada \\
\hline
\end{tabular}

Ainda destacando a perspectiva do professor a respeito do tema, temos que a agregação é, basicamente, formada por indivíduos que se amparam devido a dificuldades encontradas. Conseqüentemente, o ato de "agregar" alguém a seu domicílio caracterizava uma certa "solidariedade social”. Os "modelos" existentes para a mesma são destacados por ele, e podem ser caracterizados da seguinte forma:

\begin{tabular}{|c|}
\hline Agregados*: Idosos $\rightarrow$ Mãe viúva ou idosa \\
\hline Crianças $\rightarrow$ Podendo ser enjeitados \\
\hline
\end{tabular}

\footnotetext{
${ }^{6}$ Ibid. p 286. Em toda sua obra Caio Prado Júnior procura destacar a permanência de aspectos do passado colonial dentro do Brasil contemporâneo. Nessa direção, o autor trata de vários setores da sociedade brasileira onde o ranço colonial ainda se faz sentir. Dessa forma, uma das questões abordadas em "Formação do Brasil Contemporâneo", mais especificamente na parte do livro dedicada a "Vida Social”, diz respeito à administração colonial. Caio Prado Júnior destaca que a noção na qual se assentou a administração colonial estaria ligada, intrinsecamente, à monarquia portuguesa. Essa, por sua vez, seria caracterizada por um organismo imenso que vai do Rei, a sua cabeça e representante de Deus na terra, até o último dos seus súditos. Assim, o Estado seria uma "unidade interiça, que funciona num todo único e que, conseqüentemente, abrangeria o indivíduo em todos os seus aspectos e suas manifestações”. Seria o Leviatã hobbesiano.

${ }^{7}$ Quinta Jornada Setecentista, realizada entre os dias 26 a 28 de novembro de 2003.

8 "Lista da $2^{\mathrm{a}}$ Comp. $^{\mathrm{a}}$ (Companhia) da Ordenança da V ${ }^{\mathrm{a}}$ (Vila) de Cor ${ }^{\mathrm{a}}$. (Coritiba)" do ano de 1793. Nessa lista nominativa Gregório Gonçalves agrega também o sobrenome “Trones”, fato presenciado igualmente em outros censos.
} 


\begin{tabular}{|l|}
\hline \multicolumn{1}{|c|}{ Adultos $\rightarrow$ Podem ser agregados ao domicílio por incapacidade física } \\
\hline * Não precisam estar necessariamente no mesmo domicilio. Assim, um agregado poderia morar em uma casa \\
anexa, nos fundos do terreno do domicílio principal. Tais práticas poderiam explicar o caso de Narçiza, explicitado \\
acima. Observo que, justamente em função da complexidade que o fenômeno da agregação pode assumir, como foi \\
explicado, o autor reconhece que a aplicação deste modelo prático é limitado.
\end{tabular}

A simplicidade de grande parcela da população curitibana, e em muitos casos a pobreza significativa da mesma, pode ser observada pelo número reduzido de cativos encontrados nos domicílios arrolados dos censos. Os índices destacados nas tabelas abaixo demonstram que não havia, em comparação com a região sudeste e nordeste da Colônia, por exemplo, um grande número de proprietários de escravos, prováveis "homens bons", 9 na região de Curitiba.

\section{Curitiba. Cálculo da média de escravos por domicílio. Primeira Companhia de Ordenanças, 1793}

\begin{tabular}{|c|c|c|}
\hline $\begin{array}{c}(\mathbf{1}) \\
\text { Número de escravos por domicílio }\end{array}$ & $\begin{array}{c}\text { (2) } \\
\text { Quantidade de domicílios em função } \\
\text { do número de escravos }\end{array}$ & Produto (1) x (2) \\
\hline 00 & 221 & - \\
\hline 01 & 12 & 28 \\
\hline 02 & 14 & 24 \\
\hline 03 & 08 & 24 \\
\hline 04 & 06 & 20 \\
\hline 05 & 04 & 36 \\
\hline 06 & 06 & 49 \\
\hline 07 & 07 & 24 \\
\hline 08 & 03 & 10 \\
\hline 10 & 01 & 24 \\
\hline 12 & 02 & 26 \\
\hline 13 & 02 & 40 \\
\hline 20 & 02 & 22 \\
\hline 22 & 01 & 27 \\
\hline 27 & 01 & $\mathbf{3 6 0}$ \\
\hline Total & $\mathbf{2 9 0}$ & \\
\hline
\end{tabular}

Curitiba. Cálculo da média de escravos por domicílio. Segunda Companhia de Ordenanças, 1793.

\begin{tabular}{|c|c|c|}
\hline $\begin{array}{c}\text { (1) } \\
\text { Número de escravos por domicílio }\end{array}$ & $\begin{array}{c}\text { (2) } \\
\text { Quantidade de domicílios em função } \\
\text { do número de escravos }\end{array}$ & $\begin{array}{c}\text { (3) } \\
\text { Produto (1) x (2) }\end{array}$ \\
\hline 00 & 381 & - \\
\hline 01 & 16 & 34 \\
\hline 02 & 17 & 12 \\
\hline 03 & 04 & 44 \\
\hline 04 & 11 & 35 \\
\hline 05 & 07 & 12 \\
\hline 06 & 02 & \\
\hline
\end{tabular}

9 Resumidamente, podemos dizer que, no período colonial, o termo "bondade" referia-se, primordialmente, a aspectos socioeconômicos. Dessa forma, "homem bom” era aquele que possuía terras e escravos, além é claro, de outros bens. 


\begin{tabular}{|c|c|c|}
\hline 07 & 01 & 07 \\
\hline 08 & 01 & 08 \\
\hline 09 & 03 & 20 \\
\hline 10 & 02 & 44 \\
\hline 11 & 04 & 26 \\
\hline 13 & 02 & 15 \\
\hline 15 & 01 & 17 \\
\hline 17 & 01 & 20 \\
\hline 20 & 01 & 21 \\
\hline 21 & 01 & 24 \\
\hline 24 & 01 & 26 \\
\hline 26 & 01 & 39 \\
\hline 39 & 01 & $\mathbf{4 3 8}$ \\
\hline \multicolumn{2}{|c|}{ Metal } & $\mathbf{4 5 8}$ \\
\hline
\end{tabular}

Embora o número de proprietários possa parecer bastante representativo, estamos tratando de uma população bastante numerosa ${ }^{10}$, e a proporção de pessoas dotadas de posses de escravos em comparação com os indivíduos desprovidos dos mesmos bens é bastante inferior.

Como pode ser observado, a transcrição da documentação e sua digitalização permitem ao historiador inúmeras possibilidades interpretativas. "Do ponto de vista da Demografia Histórica, suas potencialidades de análise são imensas. Pelas listas nominativas de habitantes livres (e com certas listas mais ricas, até mesmo dos escravos), pode-se estabelecer as Fichas de reconstituição de famílias, à la Louis Henry (...)”." ${ }^{11}$

Tal citação toca em um dos objetivos principais da pesquisa: a busca de indivíduos em um conjunto de listas nominativas que, conseqüentemente, venham a auxiliar na elaboração de interpretações a respeito do contexto colonial brasileiro, mais especificamente do caso “paranaense”. Nessa direção, utilizamos como "eixo” para os estudos realizados a história de Gregório Gonçalves e sua mulher Anna Maria de Lima. Como eu me referi, o mesmo foi mencionado em um conjunto de listas nominativas, tais como as datadas de 1792 e $1797,,^{12}$ além da lista aqui utilizada do ano de 1793, pertencente à Curitiba. Conseqüentemente, buscou-se localizar também os “compadres” de Gregório nas listas a fim de incrementar as discussões a respeito da "teia” das relações sociais engendradas pelo compadrio - além de buscar, é claro, uma melhor compreensão a respeito do contexto histórico ao qual as mesmas estão inseridas.

Assim sendo, destaco a seguir de forma esquemática os “compadres” de Gregório localizados durante o desenvolvimento desta pesquisa. Entretanto, devido ao fato de que grafias distintas eram aplicadas pelos recenseadores durante a elaboração dos censos, sobre alguns nomes pairam dúvidas a respeito de sua ligação com Gregório Gonçalves.]

Testemunhas de Casamento:

Antonio do Loureiro Almeyda Carão: (?).

- Antonio Francisco Guimarães: Localizado na Primeira Companhia de Ordenanças de Curitiba no ano de 1793: Casado, 42 anos, 04 filhos, com um agregado e detentor de 03 escravos.

(João) Francisco Correa: (?).

Manoel Roque de Siqueira Coreya: (?).

\footnotetext{
${ }^{10}$ Nas listas nominativas de $1793,1^{\mathrm{a}}$ e $2^{\mathrm{a}}$ Companhia de Ordenanças, foram arrolados 4248 (quatro mil duzentos e quarenta e oito) habitantes, dos quais 2009 (dois mil e nove) são homens e 2239 (dois mil duzentos e trinta e nove) são mulheres.

${ }^{11}$ MARCÍlIO, Maria Luiza. Op. Cit, p. 47.

${ }^{12}$ NADALIN, Sergio Odilon. A demografia numa perspectiva histórica. Belo Horizonte: ABEP, 1994.
} 
Abaixo segue a relação dos padrinhos de batismo dos filhos do casal Gregório Gonçalves e Anna Maria. Os padrinhos encontrados no conjunto de listas analisadas do ano de 1793 estão em negrito.

Os filhos de Gregório Gonçalves e Anna Maria de Lima e seus padrinhos

\begin{tabular}{|c|c|}
\hline Filhos & Padrinhos \\
\hline Felisberto & $\begin{array}{c}\text { (Serafim) Antonio José da Silva e sua esposa Gertrudes } \\
\text { Batista Denis }\end{array}$ \\
\hline Bento & $\begin{array}{l}\text { Roque Sequeyra (Cortes) e sua esposa Rosa dos Santos: } \\
\text { Localizados na Segunda Companhia de Ordenanças de } \\
\text { Curitiba. Há quinze escravos no domicílio e o casal possui } \\
\text { sete filhos }\end{array}$ \\
\hline Maria & Manoel da Paixão e sua esposa Gertrudes Maria \\
\hline Jozé & $\begin{array}{l}\text { João Batista Silveira Denis (Alferes) e Maria Pereira } \\
\text { (Viúva) }\end{array}$ \\
\hline Roza & Francisco Silveira e Anna Silveira (Irmãos) \\
\hline Maria (II) & $\begin{array}{l}\text { Sebastião Álvares de Araújo e sua esposa Quitéria da } \\
\text { Sylva Pinheiro. Localizados na Segunda Companhia de } \\
\text { Ordenanças de Curitiba. Há treze escravos no domicílio e o } \\
\text { casal tem cinco filhos. }\end{array}$ \\
\hline Izabel & $\begin{array}{l}\text { Antonio Alves de Araújo (Solteiro) e Gertrudes Maria*(?) } \\
\text { (Solteira). }\end{array}$ \\
\hline Felizardo & Joaquim José da Silva e Thereza Maria de Jesus \\
\hline Anna & $\begin{array}{l}\text { José Vas Torres e sua filha solteira Thereza Vas: } \\
\text { Localizados na Segunda Companhia de Ordenanças } \\
\text { Curitiba. José é casado com Joanna Maria de Jesus e não } \\
\text { possui escravos. O casal tem mais onze filhos além de } \\
\text { Thereza. }\end{array}$ \\
\hline
\end{tabular}

* Está presente em um domicilio chefiado por Joaquim Francisco. O mesmo não possui estado civil indicado. Gertrudes Maria (?) aparece com dois filhos: um menino de 04 anos e uma menina com 05.

Observando a relação acima é possível perceber que, dos compadres de Gregório Gonçalves localizados, três dos cinco possuem um número representativo de escravos - Roque Sequeyra (Cortes), com 15 cativos; Sebastião Álvares de Araújo com 13 cativos; Antonio Francisco Guimarães com 03 cativos - considerando a "realidade curitibana” do século XVIII. Nessa direção, podemos destacar que as relações de compadrio estabeleciam-se, muitas vezes, entre pessoas pobres e ricas para constituírem-se vínculos diversos. "Trata-se, portanto, de um vínculo especial, que abre caminho para que, mesmo os grupos mais empobrecidos da população, por assim dizer, 'elejam' parentes pertencentes a grupos superiores da sociedade". ${ }^{13}$ Entretanto, é fundamental destacar que embora houvesse um "laço" entre os compadres, as diferenças sociais, digamos, continuavam bem delimitadas, pois não havia partilha de bens entre os mesmos.

Dessa forma, podemos dizer que as relações de compadrio criam uma espécie de "rede" entre as relações sociais. Infelizmente, nas listas nominativas da vila de Curitiba no ano de 1793, apenas um dos vínculos criados por Gregório Gonçalves e Anna Maria é explicitado: a ligação, já mencionada, entre nosso "protagonista” e Sebastião Álvares/Alves.

Estaria Narçiza sendo agregada no domicilio, ou no terreno, onde Gregório vivia por intermédio de Sebastião com intento de auxiliar - reforçando ai sua imagem de "protetor" - a família de seu "compadre”? É pouco provável. Talvez, Gregório estivesse locado em terras de seu compadre Sebastião, que pelo número elevado de escravos presente em seu domicílio (treze) pudesse ser um fazendeiro, sendo a agregação de Narçiza neste caso, uma "troca" de favores entre ambos. Entretanto, em nenhuma das listas nominativas transcritas nessa etapa da pesquisa ${ }^{14}$ é arrolada fazenda em nome de Sebastião Álvares/Alves, resultando assim, em outra interrogação.

De qualquer forma, o compadrio entre "desiguais" - e nada mais claro do que uma desigualdade entre Gregório e Sebastião, padrinho de sua terceira filha também chamada Maria - propiciava, aos menos abastados,

\footnotetext{
${ }^{13}$ VENANCIO, Renato Pinto. Compadrio e rede familiar entre forras de Vila Rica, 1713-1804. p. 1. In : Anais da V Jornada Setecentista.

${ }^{14}$ Primeira e Segunda Companhia de 1793 da Vila de Curitiba e a Lista da Vila de Castro do mesmo ano.
} 
proteção, auxílio e favores. ${ }^{15}$ Assim superavam-se, de certa forma, as barreiras sociais, sem abandonar, evidentemente, o caráter patriarcal presente na Colônia.

Por meio da pesquisa que está sendo efetivada pode-se constatar que os documentos utilizados são excelentes fontes de informação a respeito do contexto colonial brasileiro. Sua análise, em conjunto com leituras complementares referentes ao tema, possibilita o incremento das indagações sobre a conjuntura que aqui se estuda. Sem sombra de dúvida, aglutinado a esse objetivo primordial, o CEDOPE também garante a preservação dos documentos do passado colonial "paranaense" devido a sua digitalização e transcrição. Conseqüentemente, através de tal estudo - que não se encerra aqui - buscou-se ampliar os limites referentes à problemática das relações sociais em uma região dotada de particularidades instigantes.

Assim sendo, a guisa de conclusão, podemos auferir que, através do "estudo de casos", de particularidades, podemos expandir e enriquecer o debate historiográfico efetivado sobre o tema das relações sociais. Nessa direção, a busca por Gregório Gonçalves possibilitaria a estruturação não apenas de sua genealogia, mas também fazer transparecer questões a respeito de toda a gama de variações existentes na configuração das mesmas. E tais procedimentos, aos olhos do historiador, suscitam diversas possibilidades de análise de toda a conjuntura estudada.

Logicamente, trata-se de um objetivo a ser perseguido em um contínuo desenvolvimento deste amplo trabalho e, devido à complexidade do tema, os resultados auferidos juntamente com as questões salientadas a respeito da estruturação das relações sociais não podem ser considerados definitivos. Além do mais, a falta de certos dados nas listas nominativas impossibilita, em alguns aspectos, a superação de certas barreiras presentes neste estudo. Saliento, nessa direção, a falta de informações a respeito das ocupações dos habitantes, a idade dos escravos encontrados em certos domicílios além do problema referente à confirmação dos nomes dos compadres de Gregório Gonçalves.

\section{Referências bibliográficas}

BOTELHO, Tarcísio Rodrigues. População e nação no Brasil do século XIX. Tese de Doutorado. Universidade de São Paulo, 1999.

BURMester, Ana Maria Oliveira. A População de Curitiba no séc. XVIII 1751-1800 Segundo os Registros Paroquiais. Tese de Mestrado. Curitiba, 1974.

HAMEISTER, Martha Daisson. Na pia batismal: estratégias de interação, inserção e exclusão social entre os migrantes açorianos e a população estabelecida na vila de Rio Grande, através do estudo das relações de compadrio e parentescos fictícios (1738-1763). In : http://www.abphe.org.br/congresso2003/Textos/Abphe_2003_91.pdf

HAMEISTER, Martha Daisson. O segredo do pajé: o nome como um bem, continente do Rio Grande de São Pedro. Trabalho de Conclusão de Disciplina efetivada na Universidade Federal do Rio de Janeiro. Rio de Janeiro : 2002.

MADEIRA, Angélica ; VELOSO, Mariza. Caio Prado: Modernista, Contemporâneo. In : Descobertas do Brasil. Ed UnB, Brasília, 2001.

MARCÍLIO, Maria Luiza. Crescimento demográfico e evolução agrária paulista 1700-1836. São Paulo : Editora HUCITEC, Edusp, 2000.

NADALIN, Sérgio Odilon. A demografia numa perspectiva histórica. Belo Horizonte: ABEP, 1994.

NADALIN, Sérgio Odilon. Paraná: Ocupação do Território, População e Migrações. Curitiba : SEED, 2001.

\footnotetext{
${ }^{15}$ HAMEISTER, Martha Daisson. Na pia batismal: estratégias de interação, inserção e exclusão social entre os migrantes açorianos e a população estabelecida na vila de Rio Grande, através do estudo das relações de compadrio e parentescos fictícios (1738-1763). In : http://www.abphe.org.br/congresso2003/Textos/Abphe_2003_91.pdf
} 
PRADO JR., Caio. Formação do Brasil Contemporâneo; Colônia. (6a. ed.). São Paulo : Brasiliense, 1961.

VENANCIO, Renato Pinto. Compadrio e rede familiar entre forras de Vila Rica, 1713-1804. In : Anais da V Jornada Setecentista. 